\title{
RESEARCH
}

\section{Prevalence of HIV and hepatitis C virus infections among inmates of Ontario remand facilities}

\author{
Liviana Calzavara PhD, Nancy Ramuscak MSc, Ann N. Burchell MSc, Carol Swantee BSc, \\ Ted Myers PhD, Peter Ford MD, Margaret Fearon MB, Sue Raymond RN
}

$\infty$

See related articles pages 252 and 262

\section{ABSTRACT}

Background: Each year more than 56 ooo adult and young offenders are admitted to Ontario's remand facilities (jails, detention centres and youth centres). The prevalence of HIV infection in Ontario remand facilities was last measured over a decade ago, and no research on the prevalence of hepatitis $C$ virus (HCV) infection has been conducted in such facilities. We sought to determine the prevalence of HIV infection, $\mathrm{HCV}$ infection and HIV-HCV coinfection among inmates in Ontario's remand facilities.

Methods: A voluntary and anonymous cross-sectional prevalence study of HIV and HCV infections was conducted among people admitted to 13 selected remand facilities across Ontario between Feb. 1, 2003, and June 20, 2004. Data collection included a saliva specimen for HIV and HCV antibody screening and an interviewer-administered survey. Prevalence rates and $95 \%$ confidence intervals were calculated and examined according to demographic characteristics, region of incarceration and self-reported history of injection drug use.

Results: In total, 1877 participants provided both a saliva specimen and survey information. Among the adult participants, the prevalence of HIV infection was $2.1 \%$ among men and $1.8 \%$ among women. Adult offenders most likely to have HIV infection were older offenders ( $\geq 30$ years) and injection drug users. The prevalence of HCV infection was $15.9 \%$ among men, $30.2 \%$ among women and $54.7 \%$ among injection drug users. Adult offenders most likely to have HCV infection were women, older offenders ( $\geq 30$ years) and injection drug users. The prevalence of HCV-HIV coinfection was $1.2 \%$ among men and $1.5 \%$ among women. It was highest among older inmates and injection drug users. Among the young offenders, none was HIV positive and 1 ( $0.4 \%$ ) was HCV positive. On the basis of the study results, we estimated that 1079 HIV-positive adults and $9208 \mathrm{HCV}$-positive adults were admitted to remand facilities in Ontario from Apr. 1, 2003, to Mar. 31, 2004.

Interpretation: Adult offenders entering Ontario remand facilities have a considerably higher prevalence of HIV and HCV infections than the general population.

Une version française de ce résumé est disponible à l'adresse www.cmaj.ca/cgi/content/full/177/3/257/DCI

CMAJ 2007;177(3):257-6I
I n Canada, the prevalence of HIV and hepatitis C (HCV) infections in the general population is estimated to be $0.8 \%$ and $0.18 \%$ respectively. ${ }^{1,2}$ Studies conducted in Canadian penitentiaries have shown that the rates are alarmingly high in inmate populations. ${ }^{3-7}$ The elevated prevalence of HIV and HCV infections among inmates has been closely linked to injection drug use and the sharing of injection equipment. Reports have shown that $30 \%-50 \%$ of Canadian inmates have a history of injection drug use. . $^{3,8-10}$

Each year more than 56000 adult and young offenders in Ontario are admitted to remand facilities (jails, detention centres and youth centres), where they await the outcome of legal proceedings, serve short-term sentences $(<60$ days) or await transfer to provincial correctional centres or federal facilities. Ontario remand facilities contain the largest number of inmates in Canada. From Apr. I, 2003, to Mar. 3I, 2004, a total of 52876 adults and 3840 young offenders were remanded to custody in the province (Statistics Branch, Ontario Ministry of Community Safety and Correctional Services: unpublished data, 2005).

Remand facilities, which act as an entry point into the entire correctional system, represent an important offender population for public health concern regarding transmissible infections. They house an inmate population that not only is larger than the inmate population in federal penitentiaries and provincial correctional facilities, but also has a more rapid turnover and shorter stays. In the 2003/04 fiscal year in Ontario, the mean length of stay in a remand facility was 32.2 days, with $50 \%$ of stays lasting 9 days or less and nearly $25 \%$ of offenders having been admitted more than once during the year. ${ }^{11}$ Therefore, there is considerable movement between this population and the general population. Furthermore, many remanded inmates are awaiting transfer to provincial correctional facilities or penitentiaries, or have stays in more than one remand facility, which leads to movement within the correctional system itself and increases the opportunities for HIV and HCV transmission should risk behaviours occur.

The only study of HIV infection among inmates in Ontario's remand facilities was completed in I993, over a decade

From the HIV Social, Behavioural and Epidemiological Studies Unit (Calzavara, Ramuscak, Myers, Raymond) and the Department of Public Health Sciences (Calzavara, Myers), Faculty of Medicine, University of Toronto, Toronto; the HIV Laboratory (Swantee, Fearon), Central Public Health Laboratory, Ontario Ministry of Health and Long-Term Care, Toronto; and the Department of Medicine (Ford), Queen's University, Kingston, Ont. 
ago. It showed that $\mathrm{I} .0 \%$ of adult men, I. $2 \%$ of adult women and $0 \%$ of young offenders were HIV positive. ${ }^{12,13}$ No research has been conducted on the prevalence of HCV infection among offenders in Ontario remand facilities. Given the lack of data regarding the comparability between remand and federal penitentiary inmate populations, the HCV prevalence rates reported in research studies conducted in federal penitentiaries in Ontario or other provinces cannot be directly extrapolated to the Ontario remand population.

We sought to determine the prevalence of HIV and HCV infections among offenders admitted to Ontario remand facilities in 2003 and 2004 and to examine rates by demographic characteristics, region of incarceration and history of injection drug use.

\section{Methods}

\section{Study design}

The Ontario Remand Study was a voluntary, anonymous, cross-sectional study involving adult and young offenders admitted to selected remand facilities across Ontario between Feb. I, 2003, and June 20, 2004. The study received ethical approval from the University of Toronto's Human Subjects Review Committee and was approved by the Ministry of Community Safety and Correctional Services' Research Committee.

We used a one-stage cluster sampling method. Participants were recruited from $\mathrm{I}_{3}$ of the 28 existing remand facilities. The I 3 facilities were purposively selected to ensure adequate representation of adults and youth, males and females, and geographic regions (northern, western, eastern and central [includes Metropolitan Toronto]). Within each region, institutions with the highest weekly admission rates were selected to reduce the time and cost of data collection. During the study period, the facilities selected for recruitment contained $49 \%$ of the total number of admissions. Target recruitment quotas were established for each data collection site, and the length of the data collection period was determined by the time it took to reach the quota.

\section{Study population}

All individuals admitted to one of the selected remand facilities between Feb. I, 2003, and June 20, 2004, and who had not previously participated in the study were eligible.

Compared with the overall remand inmate population, the study sample included an overrepresentation of several subgroups. Females and young offenders (individuals charged under the Youth Criminal Justice Act [or the former Young Offender Act] and typically under the age of 18 years) were intentionally oversampled to ensure precision in calculations of disease prevalence. Aboriginal inmates were also overrepresented compared with the overall remand inmate population (I4. I\% v. 7.5\%) (Statistics Branch, Ontario Ministry of Community Safety and Correctional Services: unpublished data, 2005).

\section{Data collection}

Experienced and specially trained data collectors obtained saliva specimens and conducted interviews in a private area.
To maintain the anonymity of the participants, verbal informed consent was obtained. To improve the acceptability of the study procedures for the inmates and address safety concerns associated with syringes, saliva specimens were collected instead of serologic samples. Because HIV and HCV antibody testing based on saliva samples is not sufficiently accurate for diagnostic purposes and is not approved for diagnostic testing, and because of the desire to maintain the anonymous nature of the data collection, infected participants could not be informed of their results. However, all participants were informed of the availability of voluntary, nominal HIV and HCV antibody testing through the remand facility's health services and were provided with a list of local anonymous testing locations in the area that could be accessed upon release from the remand facility.

The data collectors obtained saliva samples using the Saliva Sampler (StatSure Diagnostic Systems Inc., Framingham, Mass.) and assigned non-identifying codes to the samples. In the interview, which lasted about IO-I5 minutes, the participants were asked about their demographic characteristics, incarceration history, medical information, and HIVand HCV-related risk behaviours. Each completed interview was given a code that matched the saliva specimen code.

HIV and HCV antibody testing was conducted at the Central Public Health Laboratory of the Ontario Ministry of Health and Long-Term Care. HIV antibody screening was conducted with the use of the DETECT HIV version I test kit (Adaltis Inc., Montréal), an enzyme-linked immunoassay (ELISA). Positive results were confirmed with the use of the Vironostika HIV-I Microelisa System (bioMérieux, Durham, NC). The assay was sensitive (98.7\%) and highly specific (I00\%). For the HCV testing, a modified version of procedures described by Van Doornum and colleagues ${ }^{14}$ was used. $\mathrm{HCV}$ antibody screening was conducted with the use of the Ortho HCV 3.0 SAVe ELISA test kit (Ortho Diagnostics, Amersham, UK). The hepatitis confirmatory testing was performed with the Bio-Rad MONOLISA anti-HCV Plus version 2 assay (Bio-Rad Laboratories Inc., Montréal). The estimated sensitivity of the assay ranged from $72 \%$ to $88 \%$, and the specificity from $89 \%$ to $100 \% .{ }^{14}$

\section{Statistical analysis}

To account for the purposive recruitment process and to ensure that the results were representative of the entire adult remand population in Ontario, the prevalence rates were weighted by region of incarceration, sex and Aboriginal status. To calculate the HIV and HCV prevalence rates (expressed as percentages), we divided the weighted number of confirmed positive test results by the weighted number of valid screening results (excluding inconclusive test results). We calculated $95 \%$ confidence intervals (CIs) using binomial approximation or exact methods, as appropriate. Prevalence rates were examined by demographic characteristics (sex, age group and Aboriginal status), self-reported history of injection drug use and region of incarceration.

HCV prevalence rates were adjusted to account for the sensitivity and specificity of the saliva screening assay. ${ }^{15}$ This adjustment was not required for the HIV prevalence rates be- 
cause of the high sensitivity and specificity of the HIV testing methodology.

The projected number of HIV- and HCV-positive adults admitted to Ontario remand facilities from Apr. I, 2003, to Mar. 3I, 2004, was estimated based on the study results. The estimated number of infected adults was the product of the total number of adult males and females admitted during that period and the weighted prevalence rate observed in the subgroup. Similarly, we estimated the upper and lower limits of the number of infected inmates on the basis of the weighted $95 \%$ CIs.

\section{Results}

During the study period, 2303 adult and young offenders were admitted to the 13 remand facilities included in the study. Sixty-four (2.8\%) were deemed ineligible to participate (they were unable to provide informed consent because of low intellectual functioning, they were intoxicated or medicated, or they had language barriers), 66 (2.9\%) were missed by the data collector, and 23I (I0.0\%) refused to participate. Thus, the overall participation rate was $84.3 \%$ (I942/2303). Refusals were highest among Aboriginal inmates $(p=0.0 \mathrm{I})$ and among inmates in the northern region $(p<0.001)$. The main reasons given for refusal included not being interested in the study (53\%), not being able to receive their HIV and $\mathrm{HCV}$ test results (7\%) and privacy concerns regarding potential DNA collection (6\%).

Participation rates were highest among non-Aboriginal inmates $(p=0.0 \mathrm{I})$ and among inmates in the eastern, central and western regions $(p<0.001)$. Of the 1942 participants, I877 (96.7\%) provided a saliva specimen and completed the survey (Table I). A history of injection drug use was reported by $30.3 \%(477 / 1576)$ of the adults and $4.7 \%$ (I4/299) of the young offenders who participated.

Twenty-five adults tested positive for HIV antibodies on saliva screening. The weighted prevalence rate was $2.0 \%$ (3I.I/I528, 95\% CI I.3\%-2.8\%). Table 2 shows the HIV prevalence rates by demographic characteristics, region of incarceration and history of injection drug use. The prevalence of HIV infection was highest among adult offenders, those aged $\geq 30$ years and those who reported a history of injection drug use.

In total, 284 adults tested positive for HCV antibodies on saliva screening. The weighted prevalence rate was $17.6 \%$ (262.4/I490, 95\%CI I7.I\%-2I.I\%). Although there were similarities between the HIV and HCV prevalence patterns (prevalence highest among adults, inmates 30 years of age or older and inmates who reported a history of injection drug use), the prevalence of HCV infection, unlike that of HIV infection, was higher among female offenders than among male offenders (Table 2).

After adjustment to account for the sensitivity and specificity of the HCV saliva screening assay, the adjusted prevalence rates for HCV infection among the adult participants ranged from $10.8 \%$ to $20.0 \%$.

Seventeen adults had coinfection with HIV and HCV. The weighted prevalence rate of coinfection was I.2\% (I8.o/I453, $95 \% \mathrm{CI} 0.7 \%-\mathrm{I} .8 \%$ ). The prevalence of coinfection was high- est among participants 30 years of age or older and those who reported a history of injection drug use (Table 2 ).

Of the 299 young offenders who participated in the study, none tested positive for HIV antibodies (o\%, o/298, 95\% CI $0.0 \%-\mathrm{I} .0 \%)$ and I tested positive for HCV antibodies $(0.4 \%$, I/286, 95\% CI 0.0I\%-2.0\%). The adjusted HCV prevalence rates ranged from $0 \%$ to $0.4 \%$.

On the basis of the study results, we estimated that 1079 HIV-positive adults (range 643-I6I8) and $9208 \mathrm{HCV}$-positive adults (range 7902-IO 52I) were admitted to Ontario remand facilities from Apr. I, 2003, to Mar. 3I, 2004.

Table 1: Characteristics of 1877 adult and young offenders in select Ontario remand facilities* who provided saliva samples for HIV and hepatitis $C$ virus antibody testing and who completed the study questionnaire

\begin{tabular}{|c|c|c|}
\hline \multirow[b]{2}{*}{ Characteristic } & \multicolumn{2}{|c|}{ No. (\%) of participants } \\
\hline & $\begin{array}{l}\text { Adult offenders } \\
\quad n=1578\end{array}$ & $\begin{array}{c}\text { Young offenders } \dagger \\
n=299\end{array}$ \\
\hline Sex & $n=1578$ & $n=299$ \\
\hline Male & $1270 \quad(80.5)$ & $277 \quad(92.6)$ \\
\hline Female & 308 (19.5) & $(7.4)$ \\
\hline Ethnic group & $n=1573$ & $n=298$ \\
\hline White & $1013(64.4)$ & 142 \\
\hline Aboriginal & 221 & $18 \quad(6.0)$ \\
\hline Black & $140 \quad(8.9)$ & $57 \quad(19.1)$ \\
\hline Other & $199(12.7)$ & $81 \quad(27.2)$ \\
\hline Place of birth & $n=1576$ & $n=299$ \\
\hline Canada & $1297 \quad(82.3)$ & $224 \quad(74.9)$ \\
\hline Elsewhere & 279 & $75 \quad(25.1)$ \\
\hline Prior incarceration & $n=1578$ & $n=298$ \\
\hline Yes & 1318 & $225 \quad(75.5)$ \\
\hline No & $260(16.5)$ & $73 \quad(24.5)$ \\
\hline $\begin{array}{l}\text { History of injection } \\
\text { drug use }\end{array}$ & $n=1576$ & $n=299$ \\
\hline Yes & $477 \quad(30.3)$ & $14 \quad(4.7)$ \\
\hline No & 1099 (69.7) & $285 \quad(95.3)$ \\
\hline $\begin{array}{l}\text { History of } \\
\text { unprotected sex }\end{array}$ & $n=1543$ & $n=293$ \\
\hline Yes & 1461 (94.7) & $229 \quad(78.2)$ \\
\hline No & $82 \quad(5.3)$ & $64 \quad(21.8)$ \\
\hline \multicolumn{3}{|l|}{$\begin{array}{l}\text { History of sex with } \\
\text { same-sex partner }\end{array}$} \\
\hline Males & $n=1259$ & $n=276$ \\
\hline Yes & $33 \quad(2.6)$ & 0 \\
\hline No & $1226(97.4)$ & $276(100.0)$ \\
\hline Females & $n=304$ & $n=22$ \\
\hline Yes & 90 (29.6) & $4 \quad(18.2)$ \\
\hline No & 214 (70.4) & $18 \quad(81.8)$ \\
\hline
\end{tabular}

*Jails, detention centres and youth centres to which people are remanded to await trial, to serve short-term sentences (<60 days) or to await transfer to correctional facilities.

†Among young offenders the mean age was 17.6 (range 16-20) years. 


\section{Interpretation}

We found that adult offenders admitted to Ontario remand facilities had a considerably higher prevalence of HIV and HCV infection, with HIV rates II times higher and HCV rates 22 times higher than those in the general population. Rates were highest among those who were older $(\geq 30$ years) and those who reported a history of injection drug use. The observed prevalence rates are comparable to those reported in other Canadian studies. ${ }^{3-9,12,13,16,17}$

Remand facilities, which act as an entry point into the entire correctional system, represent an important offender population for public health concern regarding transmissible infections. They house an inmate population larger than that in federal penitentiaries and provincial correctional facilities, but one that has a rapid turnover and short stays. Therefore, there is considerable movement between this population and the general population. Furthermore, there is movement within the correctional system because many remanded inmates are awaiting transfer to provincial correctional facilities or penitentiaries, or have stays in more than one remand facility. Such movement increases the risk of
HIV and HCV transmission should risk behaviours occur.

Since 1993, HIV prevalence rates in Ontario remand facilities have increased significantly among adult males, but they have remained fairly stable among adult females. ${ }^{12,13}$ In 1993 the prevalence among adult males was $1.0 \%$ (95\% CI $0.8 \%-$ I. $2 \%$ ), and in $2003 / 04$ it was $2.1 \%$ (95\% CI I. $3 \%-2.8 \%$ ). Among adult females, the rates were I. $2 \%$ (95\% CI $0.6 \%-$ I. $8 \%$ ) and I. $8 \%$ (95\% CI $0.4 \%-5.0 \%)$ respectively. Similar to the 1993 study results, the rates of HIV infection were highest among older inmates ( $\geq 30$ years) and those reporting a history of injection drug use.

HIV and HCV infections may pose a significant burden to health care services and a serious transmission threat. On the basis of our results, we estimated that I079 HIV-positive adults (range 643-I6I8) and $9208 \mathrm{HCV}$-positive adults (range 7902-IO 52I) were admitted to Ontario remand facilities from Apr. I, 2003, to Mar. 3I, 2004.

We found that the prevalence of HCV infection was higher among adult female offenders than among adult male offenders. Previous research has consistently reported higher rates among female inmates in penitentiaries, which suggests that female inmates are more likely than male

Table 2: Weighted prevalence of HIV infection, hepatitis $\mathrm{C}$ virus (HCV) infection and HIV-HCV coinfection among adult and young offenders, by demographic characteristics, region of incarceration and history of injection drug use

\begin{tabular}{|c|c|c|c|}
\hline \multirow[b]{2}{*}{ Variable } & \multicolumn{3}{|c|}{ Weighted prevalence* (95\% confidence interval), \% } \\
\hline & $\begin{array}{c}\text { HIV } \\
\text { infection }\end{array}$ & $\begin{array}{c}\text { HCV } \\
\text { infection }\end{array}$ & $\begin{array}{l}\text { HIV-HCV } \\
\text { coinfection }\end{array}$ \\
\hline Adult offenders & $2.0(1.3-2.8)$ & $17.6(17.1-21.1)$ & $1.2(0.7-1.8)$ \\
\hline \multicolumn{4}{|l|}{ Sex } \\
\hline Male & $2.1(1.3-2.8)$ & $15.9(14.0-17.9)$ & $1.2(0.6-1.8)$ \\
\hline Female & $1.8(0.4-5.0)$ & $30.2(23.5-37.0)$ & $1.5(0.3-4.8)$ \\
\hline \multicolumn{4}{|c|}{$\begin{array}{l}\text { Region of incarceration } \\
\text { in Ontario }\end{array}$} \\
\hline Northern & $0.3(0.0003-2.4)$ & $15.1(10.0-20.2)$ & $0.3(0.0003-2.6)$ \\
\hline Eastern & $2.7(0.9-4.6)$ & $25.1(20.1-30.0)$ & $2.2(0.5-3.9)$ \\
\hline Central & $2.9(1.6-4.2)$ & $16.5(13.6-19.4)$ & $1.2(0.4-2.1)$ \\
\hline Western & $1.0(0.3-2.5)$ & $15.0(11.5-18.6)$ & $1.0(0.3-2.7)$ \\
\hline \multicolumn{4}{|l|}{ Age group, yr } \\
\hline $18-29$ & $0.2(0.01-0.9)$ & $4.7 \quad(3.1-6.3)$ & $0.1(0.0001-0.8)$ \\
\hline $30-39$ & $2.7(1.2-4.2)$ & $21.8(17.9-25.8)$ & $1.1(0.3-2.6)$ \\
\hline $40-49$ & $3.0(1.2-4.9)$ & $36.2(30.9-41.6)$ & $2.9(1.0-4.8)$ \\
\hline$\geq 50$ & $8.8(3.1-14.4)$ & $26.4(17.5-35.4)$ & $4.6(1.3-11.6)$ \\
\hline \multicolumn{4}{|l|}{ Injection drug use } \\
\hline Yes & 5.7 (3.5-7.9) & 54.7 (49.8-59.6) & $4.4(2.4-6.4)$ \\
\hline No & $0.7(0.2-1.1)$ & $4.1 \quad(2.9-5.2)$ & $0.1(0.0-0.5)$ \\
\hline \multicolumn{4}{|l|}{ Aboriginal status } \\
\hline Aboriginal & $0.0(0.0-2.5)$ & $16.6 \quad(9.8-23.4)$ & $0.0(0.0-2.6)$ \\
\hline Non-Aboriginal & $2.2(1.4-3.0)$ & 17.7 (15.7-19.7) & $1.3(0.7-2.0)$ \\
\hline Young offenders & $0.0(0.0-1.0)$ & $0.4 \quad(0.01-2.0)$ & $0.0(0.0-1.0)$ \\
\hline
\end{tabular}

*Weighted by sex, Aboriginal status and region of incarceration (not for young offenders). 
inmates to have a history of injection drug use and are at greater risk of HIV and HCV infection based on needlesharing behaviours. ${ }^{18}$

The relation between HIV and HCV infection and age has been shown in previous research and represents the increased risk of infection with increased length of exposure associated with risk behaviour (i.e., injection drug use). ${ }^{19}$ In Ontario, between 1985 and 2003 , two-thirds of people found to be HIV positive were aged 25-44 years (mean age at diagnosis 34.3 years)..$^{20}$

The prevalence of HIV and HCV infection among young offenders in our study was low or nonexistent ( $0 \%$ and $0.4 \%$ respectively). In 1993, the observed prevalence of HIV among young offenders was also ०\%. ${ }^{12,13}$ Despite the low levels of current infection, reported high levels of injection drug use and other risk behaviours indicate the need for education and prevention messages targeted at this population.

Given the general consistency regarding HIV and HCV prevalence rates between provinces across Canada reported in previous studies, ${ }^{3-9,12,13,16,17}$ the findings in our study may indicate high rates of HIV and HCV infections among offender populations in other provinces. Our results may be rationale for further study to gauge the scope of the problem in offender populations across Canada.

Our study had limitations. The study design allowed for the determination of prevalent, rather than incident, cases of HIV and HCV. Analysis of prevalent cases does not allow for the inference of a causal relation between a characteristic and infection. Second, the self-report of risk behaviours, especially those of a sensitive or illegal nature, may lead to the underreporting of risk behaviours within the correctional setting. Finally, the use of saliva specimens instead of blood samples for HCV antibody screening may lead to outcome misclassification. However, we adjusted the HCV prevalence rate to account for the sensitivity and specificity of the assay.

In conclusion, HIV and HCV infections are significant health issues that face inmate populations. Given the considerable movement between the remand inmate population and the general population, as well as the movement of inmates between facilities within the correctional system, there are opportunities for HIV and HCV transmission should risk behaviours occur. Because of this risk of transmission during incarceration and after release, relevant and targeted education and prevention efforts are important. Incarceration may provide an important opportunity for HIV and HCV antibody testing, education, prevention, care and treatment in a highrisk population.

This article has been peer reviewed.

Competing interests: None declared.

Contributors: All authors have been directly involved in the design and conduct of the research study, have provided input into the draft manuscript and have given approval of the final version for publication.
Acknowledgements: The authors thank those who assisted the Ontario Remand Study and who contributed to this manuscript. We thank the inmates who participated in the study, the health care coordinators, management and staff at each of the data collection facilities, the data collectors, Joanne Shaw of the Ontario Ministry of Community Safety and Correctional Services, and Carol Major, formerly of the HIV Laboratory, Ontario Ministry of Health and Long-Term Care. We especially thank Dr. Paul Humphries for his assistance with the implementation of the study.

This study was supported by a grant from the Ontario HIV Treatment Network.

\section{REFERENCES}

I. Hepatitis $C$ information for health professionals. Ottawa: Health Canada; 2002 Cat no H39-6or/2002E. Available: www.phac-aspc.gc.ca/hepc/pubs/pdf/hepcinfo -healthprof_e.pdf (accessed 2007 June I).

2. HIV/AIDS EPI updates. Ottawa: Health Canada; 2004. Cat no H39-I/I-2004E-PDF. Available: www.phac-aspc.gc.ca/publicat/epiu-aepi/epi_update_may_04/pdf/epi _may_2004_e.pdf (accessed 2007 June I)

3. Ford PM, Pearson M, Sankar-Mistry P, et al. HIV, hepatitis C and risk behaviour in a Canadian medium-security federal penitentiary. Queen's University HIV Prison Study Group. QJM 2000;93:II3-9.

4. De P, Connor N, Bouchard F, et al. HIV and hepatitis C virus testing and seropositivity rates in Canadian federal penitentiaries: a critical opportunity for care and prevention. Can J Infect Dis Med Microbiol 2004;15:22I-5.

5. Ford PM. Voluntary Screening for hepatitis $\mathrm{C}$ in a Canadian federal penitentiary for men. Can Commun Dis Rep I995;2I:I34-6.

6. Prefontaine R, Chauhary R, Mathias R. Analysis of risk factors associated with hepatitis $\mathrm{B}$ and $\mathrm{C}$ infection in correctional institutions in British Columbia. Can J Infect Dis I994:5:153-6.

7. Smith J. Viral hepatitis in Canadian federal penitentiaries. Focus Infect Dis 2005 3(I):I-2. Available: www.csc-scc.gc.ca/text/pblct/hsbulletin/2005/nor/2_e.shtml (accessed 2007 June I).

8. Dufour A, Alary M, Poulin C, et al. Prevalence and risk behaviours for HIV infection among inmates of a provincial prison in Quebec City. AIDS 1996;10:1009-15.

9. Rothon D, Mathias R, Schecter M. Prevalence of HIV infection in provincial prisons in British Columbia. CMAJ I994;I5I:78I-7.

Io. Calzavara L, Burchell A, Schlossberg J, et al. Prior opiate injection and incarceration history predict injection drug use among inmates. Addiction 2003;98:1257-65.

II. Annual correctional statistics - 2003/04. Toronto: Program Effectiveness, Statistics and Applied Research Unit, Correctional Services Division, Ontario Ministry of Community Safety and Correctional Services.

I2. Calzavara L, Major C, Myers T, et al. Reducing volunteer bias: using left-over specimens to estimate rates of HIV infection among inmates in Ontario, Canada. AIDS I995;9:63I-7.

I3. Calzavara L, Major C, Myers T, et al. The prevalence of HIV-I infection among inmates in Ontario, Canada. Can J Public Health 1995;86:335-9.

I4. Van Doornum GJJ, Lodder A, Buimer M, et al. Evaluation of hepatitis C antibody testing in saliva specimens collected by two different systems in comparison with HCV antibody and HCV RNA in serum. JMed Virol 200I;64:I3-20.

I5. Greenland S. Basic methods for sensitivity analysis and external adjustment. In: Rothman KJ, Greenland S, editors. Modern epidemiology. 2nd ed. Philadelphia: Lippincott Williams \& Wilkins; 1998. p. 343-57.

I6. Hankins C, Gendron S, Handley M, et al. HIV infection among women in prison: an assessment of risk factors using a non-nominal methodology. Am J Public Health $1994 ; 84: 1637-40$.

I7. Hankins C, Gendron S, Richard C, et al. HIV-I infection in a medium security prison for women - Quebec. Can Dis Wkly Rep I989;15:I68-70.

I8. Pongrac MB. HIV, hepatitis C virus (HCV) in women offenders - Why are the rates so high? Focus Infect Dis 2002;I(2):5-6. Available: www.csc-scc.gc.ca/text /pblct/hsbulletin/2002/no2/4_e.shtml (accessed 2007 June I).

I9. Gates J, Post J, Kaldor J, et al. Risk factors for hepatitis C infection and perception of antibody status among male prison inmates in the Hepatitis $\mathrm{C}$ Incidence and Transmission in Prisons Study cohort, Australia. J Urban Health 2004;81:448-52.

20. Remis RS, Swantee C, Rottensten K, et al. Report on HIV/AIDS in Ontario 2003 Toronto: Ontario Ministry of Health and Long-Term Care; 2004. Available: www.phs.utoronto.ca/ohemu/doc/PHEROo3R.pdf (accessed 2007 June 25].

Correspondence to: Dr. Liviana Calzavara, HIV Social Behavioural and Epidemiological Studies Unit, Department of Public Health Sciences, University of Toronto, 5 th floor, Health Sciences Building, ${ }_{55}$ College Street, Toronto ON $\mathrm{M}_{5} \mathrm{~T}_{3} \mathrm{M} 7$; fax 4I6 97I-2704; liviana.calzavara@utoronto.ca 